\title{
Ensino de Odontologia Legal no Brasil: um convite à reflexão
}

Hélion Leão Lino-Júnior*, Mariana Gabriel**, Eduardo Daruge-Júnior***, Ricardo Henrique Alves da Silva****

\author{
* Professor, Odontologia Legal, Universidade Estadual de \\ Londrina - UEL. \\ ** Doutoranda em Odontologia Social, Faculdade de \\ Odontologia de São Paulo - FOUSP. \\ *** Professor, Odontologia Legal, Faculdade de Odontologia \\ de Piracicaba - UNICAMP. \\ **** Professor, Odontologia Legal, Faculdade de Odontologia \\ de Ribeirão Preto - USP.
}

\section{RESUMO}

Com a intensa evolução da sociedade, o ensino na Odontologia Legal vem passando por significativas transformações nos últimos anos, para atender às demandas sociais solicitadas. $\mathrm{O}$ novo profissional, além de vislumbrar notáveis perspectivas na área, vem recebendo informações importantes sobre mercado de trabalho, que o auxiliarão a exercer as atividades clínicas dentro de um contexto administrativo, ético e legal organizados. Desta forma, objetivo desse trabalho é apresentar pontos para reflexão no tocante ao processo de ensinoaprendizagem na área de Odontologia Legal, nos cursos de graduação em Odontologia. A partir de diversas discussões realizadas pela Associação Brasileira de Ética e Odontologia Legal (ABOL) e pela Associação Brasileira de Ensino Odontológico (ABENO) reuniram-se nesse trabalho aspectos atuais das discussões do ensino nessa área, evidenciando a necessidade do trabalho conjunto de todas as IES interessadas neste processo de ensino- aprendizagem em Odontologia, na busca da excelência da profissão.

Descritores: Odontologia Legal. Educação em Odontologia. Educação Superior.

\section{INTRODUÇÃO}

O ensino da Odontologia vem passando por grandes transformações. $\mathrm{O}$ novo profissional, além de acrescentar notáveis perspectivas na área, vem recebendo informações importantes da evolução do mercado de trabalho, auxiliando-o na organização administrativa do consultório. Nessa perspectiva, cada vez mais a integração curricular vem se mostrando como um promissor meio de avançar nessa proposta ${ }^{1}$. Busca-se o rompimento com os paradigmas das disciplinas estanques e posiciona-se no sentido de parcerias entre os sujeitos do processo, ou seja, professores entre si, e professores e alunos, na busca de responsabilidades conjugadas $^{2}$.

Além disso, a formação deve ser alicerçada no desenvolvimento de competências necessárias para subsidiar 
o profissional em suas tomadas de decisões. Segundo as Diretrizes Curriculares Nacionais ${ }^{3}$ (DCN) para os cursos de Odontologia, essas competências devem fazer parte de uma gama de competências que extrapola o elemento técnico da profissão, ou seja, além das Ciências Odontológicas, das Ciências Biológicas e da Saúde, o profissional deve estar capacitado nas Ciências Humanas e Sociais.

De acordo com Mendes ${ }^{4}$ e Paula ${ }^{5}$, historicamente, na formação acadêmica do cirurgião-dentista, a tendência sempre foi a maior valorização das atividades curativas, inclinada ao desenvolvimento técnico-científico, carente de discussões éticas e dependentes de tecnologia de ponta. Com os currículos acadêmicos divididos em microdisciplinas e focados mais na doença do que, no próprio paciente, exige-se a utilização das necessidades epidemiológicas, econômicas, além das sociais.

Em sintonia com essas aspirações, a Odontologia Legal traduzse como uma disciplina fundamental na articulação dessa proposta, uma vez que mostra ao aluno a importância da responsabilidade ética e legal no exercício da profissão. No entanto, mesmo após a implantação das DCN, ainda se observam alguns cursos de graduação em Odontologia em dissonância com a necessidade de se formar profissionais fortemente pautados em valores éticos ${ }^{6}$. Essa dificuldade de fortalecimento da disciplina de Odontologia Legal, não é observada, apenas, no Brasil. Os Estados Unidos, por exemplo, vêm sinalizando, desde 1960, a necessidade de os cursos de Odontologia valorizarem essa área de conhecimento dentro de seus currículos ${ }^{7}$.

Perante esse quadro, os conteúdos programáticos das disciplinas de Deontologia e Diceologia, vinculados à área da Odontologia Legal, ganham valores superlativos e assumem real importância na formação do acadêmico. $\mathrm{Na}$ prática, constata-se um aumento significativo na procura de informação e formação profissional nessa área, mostrando que o tema, além de atual e necessário, é um campo amplo a ser explorado ${ }^{8}$.

Com base no exposto o objetivo desse trabalho é apresentar pontos para reflexão no tocante ao processo de ensino-aprendizagem na área de Odontologia Legal, nos cursos de graduação em Odontologia.

\section{HISTÓRICO DO ENSINO DA ODONTOLOGIA LEGAL}

Após 44 anos da criação da primeira escola de Odontologia do mundo, a Universidade de Maryland School of Dentistry, antiga Baltimore College of Dental Surgery, em Baltimore, nos EUA, em $1840^{9}$, oficializou-se tardiamente o ensino odontológico brasileiro. Em 25 de outubro de 1884 , por meio do Decreto Imperial $\mathrm{n}^{\mathrm{o}} .9 .311^{10}$, o curso era vinculado às Faculdades de Medicina do Rio de Janeiro e da Bahia, com duração de três anos, contemplando matérias como anatomia, histologia, fisiologia, higiene, patologia, terapêuticas dentárias, clínica odontológica e prótese dentária ${ }^{11}$.

Historicamente associadas na prática e no ensino, a Odontologia sempre foi considerada como uma especialidade da Medicina, haja vista, onde, em diversos países, o cirurgião- 
dentista, estomatologista é, de fato, um médico especialista. No mesmo sentido, é cediço que a Odontologia Legal constitui, a rigor, um dos ramos da Medicina Legal, colaborando também com a justiça, ao realizar exames especializados referentes aos arcos dentais e a suas estruturas correlatas, já que se entende não ser possível e adequado avaliar isoladamente uma parte do sistema humano, dissociando-a do todo, sem analisar as modificações e implicações que a sua disfunção acarretaria no organismo. Neste sentido, verificam-se muitos registros históricos desta associação, sendo a primeira publicação oficial registrada em Paris, no ano de 1898, intitulada "Arte Dentária", do cirurgião-dentista cubano Oscar Amoedo, onde a Odontologia Legal foi reconhecida de fato, como uma ciência capaz de auxiliar a Medicina Legal, evidenciando o liame fundamental existente entre a Odontologia e o Direito, ao mesmo tempo em que abriu definitivamente caminho para a instituição da disciplina, no ensino odontológico $^{12}$. Porém, passados 35 anos, o curso de Odontologia, no Brasil, ganhou autonomia e desvinculou-se do curso de Medicina, por meio do Decreto promulgado pelo presidente Epitácio Pessoa, no dia 29 de novembro de 1919. Todavia, somente em 1925, tornou-se a Faculdade de Odontologia do Rio de Janeiro, mantendo a duração do curso em três anos até 1947, quando, a partir de então, passou a oferecer o currículo em 4 $\operatorname{anos}^{8}$.

Somente em 11 de abril 1931, com as modificações na nova proposta curricular é que se verifica, no art. 218, por meio do Decreto $\mathrm{n}^{\circ}$ 19.852, a inclusão oficial da disciplina de
Odontologia Legal, dentre outras, no curso de Odontologia ${ }^{13}$. Com o passar dos anos, a disciplina de Odontologia Legal ministrada até então na graduação, foi se consolidando e passou a ser ofertada, também, no nível lato sensu, com cursos de especialização, e, posteriormente, no nível stricto sensu, para Mestrado e Doutorado ${ }^{12}$.

Atualmente, de acordo com os dados estatísticos do $\mathrm{CFO}^{14}$, a especialidade conta com 600 profissionais, em um universo de 266.000 cirurgiões-dentistas, regularmente inscritos nesta Autarquia. Comparando-a com outras especialidades, como a Ortodontia que conta com 13.211 especialistas, e a Implantodontia que perfaz 10.714 especialistas, nota-se que a Odontologia Legal, apesar de ser área de conhecimento específico, ligando a ciência odontológica com a ciência jurídica, na prática profissional, ela se correlaciona com todas as demais especialidades da Odontologia, e é, ainda, uma especialidade em expansão e com potencial mercadológico a ser explorado, podendo gerar oportunidades de trabalho, a julgar pelos relevantes serviços que presta à Justiça e à sociedade, produzindo implicações diretas na vida profissional do cirurgiãodentista e nas suas relações sociais e humanas.

A denominação "Odontologia Legal", de acordo com o entendimento aceito, foi criada pelo Professor Emérito paulista, Luiz Lustosa Silva, sendo o mesmo, autor da primeira obra brasileira - "Odontologia Legal”, publicada em 1924, que se referiu especificamente à disciplina com este título e estabeleceu os primeiros limites do campo de 
atuação. Em razão da extensão e das muitas possibilidades de ação, considera-se que a finalidade principal da Odontologia Legal seja a aplicação dos conhecimentos da ciência odontológica a serviço da justiça ${ }^{12}$, sendo reconhecida pelo Conselho Federal de Odontologia, por meio da Resolução 63/2005, atualizada em 2012, como uma de suas 19 especialidades.

"SEÇÃO VIII - Odontologia Legal Art. 63. Odontologia Legal é a especialidade que tem como objetivo a pesquisa de fenômenos psíquicos, físicos, químicos e biológicos que podem atingir ou ter atingido o homem, vivo, morto ou ossada, e mesmo fragmentos ou vestígios, resultando lesões parciais ou totais reversíveis ou irreversíveis.

Parágrafo único. A atuação da Odontologia Legal restringe-se à análise, perícia e avaliação de eventos relacionados com a área de competência do cirurgiãodentista, podendo, se as circunstâncias o exigirem estender-se a outras áreas, se disso depender à busca da verdade, no estrito interesse da justiça e da administração."

Já no artigo 64 da mesma codificação administrativa, podem-se compreender as áreas de competência para atuação do especialista em Odontologia Legal, que incluem: a) identificação humana; b) perícia em foro civil, criminal e trabalhista; c) perícia em área administrativa; d) perícia, avaliação e planejamento em infortunística; e) tanatologia forense; f) elaboração de: 1) autos, laudos e pareceres; 2) relatórios e atestados; g) traumatologia odonto legal; h) balística forense; i) perícia logística no vivo, no morto, íntegro ou em suas partes em fragmentos; j) perícia em vestígios correlatos, inclusive de manchas ou líquidos oriundos da cavidade bucal ou nela presentes; k) exames por imagem para fins periciais; 1) deontologia odontológica; m) orientação Odontolegal para o exercício profissional; e, $\mathrm{n}$ ) exames por imagens para fins odontolegais.

\section{PONTOS PARA REFLEXÃO SOBRE O ENSINO NA ODONTO- LOGIA LEGAL}

Todos os seres humanos são seres sociais, relacionando-se uns com os outros de diversas maneiras, desde a família até a participação social e política. A assistência odontológica deve ter, como referência, o reconhecimento da pessoa humana, como um ser único, portador de anseios, medos, expectativas, virtudes, defeitos e vulnerabilidades. As relações interpessoais, envolvendo profissionais, pacientes e membros da equipe de saúde, devem ser pautadas em respeito e confiança por meio de uma conduta ética.

O estudante de Odontologia está sujeito às normas éticas, assim como qualquer indivíduo. Obrigatoriamente, o aluno deve ser instruído, como o é, a respeito dos princípios e normas éticas, bem como legais, para que tenha todos os pré-requisitos e condições de praticálas, adquirindo, dessa maneira, uma formação moral impoluta, em conjunto com as formações técnico-científicas. Este preparo, para o exercício das atividades profissionais, deve dar-se 
continuamente, desde a graduação até os cursos de educação continuada ${ }^{15}$.

No entanto, muitas vezes, as disciplinas não clínicas, como por exemplo, a Odontologia Legal, é vista com certo desdém pelos acadêmicos, principalmente, nos primeiros anos do curso, uma vez que a maioria ingressa já com uma especialidade aparentemente definida e, assim, tende a segregar e a priorizar sua formação de maneira imatura e errônea. Além disso, os professores, também, estão acostumados a uma lógica de ensinamento de competências técnicas e, por vezes, apresentam dificuldade na construção de outros saberes necessários à profissão ${ }^{16}$. Esse é um desafio imposto e que precisa ser superado, para isso, inicialmente é necessário refletir: Quem é o estudante de Odontologia dos dias atuais?

\section{Nova Geração}

As Instituições de Ensino Superior (IES) precisam inovar em seus formatos educacionais para avançar no desenvolvimento de competências e motivar seus graduandos de maneira efetiva. Sangiorgio e colaboradores alertam que os estudantes que frequentam, atualmente, as universidades são pertencentes à "Geração Y", ou seja, uma geração conectada às tendências globais, que constroem o conhecimento de maneira dinâmica $\mathrm{e}$ que não respondem a modelos educacionais centrados nos professores ${ }^{17}$. Nesse novo cenário educacional, as Tecnologias de Informação e Comunicação (TIC) têm sido cada vez mais incorporadas na área da saúde, onde os cursos de graduação podem lançar mão de estratégias de recursos educacionais interativos com seus alunos para apoiar o processo ensinoaprendizagem e motivá-los ao conhecimento $^{18}$. Na Odontologia Legal são inúmeros os conteúdos que podem ser abordados dentro dessa nova perspectiva e contribuir para a mudança de visão do acadêmico frente à disciplina. Mas por onde começar?

\section{Discutir para avançar}

Atenta a esta realidade, a ABENO - Associação Brasileira de Ensino Odontológico promoveu na $47^{\mathrm{a}}$. Reunião da ABENO, a $1^{\mathrm{a}}$. Reunião Paralela de Professores de Odontologia Legal, onde se discutiu amplamente o ensino dessa disciplina, em nível de graduação e pós-graduação, e foram evidenciadas as carências e as necessidades da área entre outras, como a falta de padronização de seu nome nos currículos de graduação, a identificação do nível de formação acadêmica do docente de Odontologia que ministra os conteúdos de Odontologia Legal, nas IES brasileiras, conteúdos programáticos da ementa da disciplina, suas distribuições de carga horária e locações ao longo do curso.

Com base nas discussões promovidas e em reflexões resultantes de outros eventos dedicados ao estudo do conteúdo mínimo da disciplina, da nomenclatura a ser adotada e ao seu período de inserção da grade curricular, desenvolvidas pela Associação Brasileira de Ética e Odontologia Legal (ABOL) como na $1^{\mathrm{a}}$. Reunião de Professores de Deontologia e Odontologia Legal (2009) e a $2^{\text {a }}$. Reunião de Professores de Deontologia e Odontologia Legal (2010), a ABOL, entidade constituída de docentes, peritos, especialistas da área em questão, 
produziu e encaminhou um ofício à ABENO orientando que os conteúdos disciplinares fossem divididos em, pelo menos, dois períodos, com cargas horárias mínimas de $60 \mathrm{~h}$ cada, reforçando no mesmo documento que: “... entende e respeita a prerrogativa de cada instituição e seu corpo docente de planejarem e executarem as disciplinas, na busca da formação de um cirurgiãodentista com base no estabelecido nas Diretrizes Curriculares Nacionais".

De acordo com a $\mathrm{ABOL}^{19}$, o primeiro período de ensino voltado para a Odontologia Legal deveria contemplar os conhecimentos de Deontologia e Diceologia, sendo ministradas de forma concomitante ao início das disciplinas clínicas e abranger, ao menos, o seguinte conteúdo programático: (I) Código de Ética Odontológica e Código de Processo Ético; (II) Lei 5081/66; (III) Exercício Lícito e Ilícito da Profissão; (IV) Responsabilidade Profissional; (V) Código de Defesa do Consumidor e sua relação com a Odontologia; (VI) Documentação Odontológica; (VII) Honorários Profissionais; (VIII) Sigilo Profissional; (IX) Noções de Direito; (X) Abertura e montagem do empreendimento odontológico no que se refere aos aspectos éticos e legais; e (XI) Atividades práticas referentes ao conteúdo ministrado.

Já, na segunda parte, a disciplina deve ser ministrada nos últimos períodos da graduação, possibilitando entendimento efetivo por parte dos alunos, nesse momento, já mais amadurecidos, e com base teórica e prática dos mais diversos campos da Odontologia Legal. O conteúdo mínimo abordará: (I) Evolução histórica da Odontologia Legal; (II) Perícias e Peritos; (III)
Identidade e Identificação; (IV) Traumatologia Forense; (V) Tanatologia Forense; (VI) Antropologia Forense; (VII) Infortunística; (VIII) Genética Forense; (IX) Balística Forense; (X) Marcas de mordidas; (XI) Atividades práticas.

No entanto, para muitos, a disciplina de Odontologia Legal tem como enfoque apenas "ensinar" o Código de Ética da profissão, quando, na verdade, se verifica um panorama pedagógico muito mais amplo e abrangente, sendo necessário ir além. $\mathrm{O}$ ensino do Código de Ética deve ser baseado em casos e situações reais, a fim de permitir o adequado entendimento de tão importante codificação. E a disciplina não pode ter como enfoque exclusivo tal normativa. A área é muito mais ampla e deve ser apresentada como tal, por profissionais que conheçam e militem verdadeiramente nessa seara. $\mathrm{O}$ aluno precisa de espaços concretos que o sensibilize para essa postura, e as demais disciplinas do currículo, desde o primeiro ano de graduação, portanto, pode e deve ser constante a sua prática nos conteúdos abordados nas salas de aulas, de maneira que todos se inteirem do conteúdo de maneira progressiva ${ }^{20}$. Além disso, os ambientes virtuais de aprendizagem, como por exemplo, blogs, chats e fóruns podem ser grandes aliados nas discussões dos assuntos éticos envolvidos no dia a dia da clínica odontológica, facilitando a comunicação e aprendizagem dos alunos. Silva aponta que algumas temáticas importantes podem ser abordadas dentro da disciplina, como a verificação da qualidade do preenchimento dos prontuários da instituição; visitas em 
clínicas particulares e públicas, visando uma melhor compreensão das normas sanitária vigentes; elaboração de documentos próprios, dentre outros.

\section{Possibilidades de mercado de trabalho}

Tendo em vista a constante mudança do perfil do cirurgião-dentista e do mercado de trabalho, as universidades devem se preocupar em formar profissionais capazes de direcionar seus conhecimentos nas diversas áreas e apresentar para o estudante as diferentes possibilidades de atuação. Mas fica a dúvida, será que os cursos estão sendo eficientes nessa apresentação? O campo da Odontologia Legal é promissor e pode ser a escolha pretendida pelo futuro profissional, podendo, depois de verificada a sua formação, inserir-se adequadamente no contexto proposto.

A pós-graduação em Odontologia Legal vem se ampliando nos últimos anos e permitindo ao profissional adquirir mais embasamento teórico, cientifico e prático para exercer a atividade profissional com segurança e valoração. Ao optar pela especialização em nível do lato sensu, as atividades periciais, cíveis, criminais e trabalhistas, ganham destaque e constituem-se em excelentes oportunidades, seja em nível privado ou público ${ }^{8}$. Já no nível do stricto sensu, o ingresso na carreira docente e na área da pesquisa em ciências forenses, também, constitui um amplo leque de possibilidades para o pós-graduando.

\section{Desafios futuros}

É evidente que a Odontologia Legal evoluiu sobremaneira e de forma rápida ao longo dos últimos anos, principalmente, a partir da reestruturação curricular ocorrida em 2002. No entanto, ainda, é notória a dificuldade de articulação institucional das IES e, também, a dificuldade de troca de informações entre as instituições para superar os desafios impostos por esta evolução. Percebe-se que cada IES apresenta características próprias para articular o ensino e a aprendizagem de seus alunos nessa área, algumas com infraestruturas modernas, adequadas e com grandes tecnologias; outras, com inovações em dinâmicas metodológicas, enfim, uma variada lista de boas práticas que, certamente, podem ser aplicadas dentro das diferentes realidades de ensino. O que chama a atenção e faz-se necessário compartilhar, é a evidente necessidade de os pares se fortalecerem como grupo, dentro desta importantíssima área de conhecimento, criando novas oportunidades de discussão para enfrentar os diversos desafios no ensino da disciplina, e, mais do que isso, trocar experiências, estabelecendo uma dinâmica de interação homogênea e produtiva para todos, seja em ambientes virtuais ou presenciais, aproximando, cada vez mais, a academia com a realidade existente.

\section{CONSIDERAÇÕES FINAIS}

Perante o exposto, alguns pontos que merecem reflexão, entre eles, a nova geração de profissionais, a necessidade do trabalho em equipe, a necessidade de apresentar as diferentes possibilidades de mercado para o estudante e os desafios futuros para o fortalecimento da Odontologia Legal como uma importante e necessária vertente da área da saúde. Destaca que, certamente, as 
IES têm um papel fundamental na continuidade dos avanços alcançados, de modo a superar os desafios impostos e motivar todos os envolvidos no processo. Além disso, convida, também, para que todos participem ativamente dessa discussão em busca de trocas de boas práticas por meio dos debates referentes a essa temática.

\section{Agradecimentos}

À Associação Brasileira de Ética e Odontologia Legal (ABOL) pela seriedade e compromisso com o ensino da Odontologia Legal e à Associação Brasileira de Ensino Odontológico (ABENO), por viabilizar e dar voz a essas discussões.

\section{REFERÊNCIAS}

1. Ditmyer MM, Mobley CC, Davenport WD. Evaluation of an Integrative Model for Professional Development and Research in a Dental Curriculum. Journal of dental education. 2014;78(3):36879.

2. Anastasiou LDGC. "Ensinar, aprender, apreender e processos de ensinagem." Processos de ensinagem na universidade: pressupostos para as estratégias de trabalho em aula. 2003. p. 15-43.

3. Brasil. Ministério da Educação. Conselho Nacional de Educação. Câmara de Educação Superior. Resolução CNE/CES 3, de 19 fevereiro de 2002. Institui Diretrizes Curriculares Nacionais do Curso de Graduação em Odontologia. Disponível em: http://portal.mec. gov.br/cne/arquivos/pdf/CES03200 2.

4. Mendes EV MB. Odontologia
Integral: bases teóricas e suas implicações no ensino e na pesquisa odontológica. 1985.

5. Paula L, Bezerra ACB. A estrutura curricular dos cursos de Odontologia no Brasil. Rev ABENO. 2003;3(1):7-14.

6. Musse JO, Boing AF, Martino FS, Silva RHA, Vaccarezza GF, Ramos DLP. O Ensino da bioética nos cursos de graduação em odontologia do estado de São Paulo. Arq Ciênc Saúde. 2007;14(1):13-6.

7. Hermsen KP, Johnson JD. A model for forensic dental education in the predoctoral dental school curriculum. J Dent Educ. 2012; 76(5):553-61.

8. Silva, RHA. Orientação Profissional para o cirurgião-dentista: ética e legislação. Editora Santos 2011.

9. McCauley HB. The first dental college: emergence of dentistry as an autonomous profession. $\mathrm{J}$ His Dent. 2003;51(1):41-5.

10. Decreto no. 9.311 de 25 de outubro de 1.884. Coleção das Leis do Império do Brasil de 1884. Parte I. Tomo XXI, Parte II. Tomo XLVII. Rio de Janeiro: Typographia Nacional, 1984.

11. Estatuto das Faculdades de Medicina. Coleção das Leis do Império do Brasil de 1884. Parte I. Tomo XXI, Parte II. Tomo XLVII. Rio de Janeiro: Typographia Nacional; 1865.

12. Paulete-Vanrell J. Odontologia legal e antropologia forense: Guanabara Koogan; 2002.

13 Brasil. Decreto no. 19.852 de 11 de abril 1931: Dispõe sobre a organização da Universidade do Rio de Janeiro. Rio de Janeiro: 
Presidência da República; 1931.

14 Conselho Federal de Odontologia. Dados Estatísticos. Rio de Janeiro, 2015. Disponível em: http://cfo.org. br/servicos-econsultas/dados-estatis ticos/

15 Samico AHR, Menezes JDV, Silva M. Aspectos éticos e legais do exercício da odontologia. 2. ed. Rio de Janeiro: Conselho Federal de Odontologia; 1994.

16 Donate-Bartfield E, Lobb WK, Roucka TM. Teaching culturally sensitive care to dental students: A multidisciplinary approach. J Dent Educ. 2014;78(3):454-64.

17 Sangiorgio JPM, Gabriel M, Moreira FS, Tanaka EE. Geração Y: a motivação para construção do conhecimento. Rev ABENO. 2011; 11(2):14-8.

18 Haddad AE, Bönecker M, SkeltonMacedo MC. Research in the field of health, dentistry, telehealth and teledentistry. Braz Oral Res. 2014; 28(1):1-2.

19 ABENO Associação Brasileira de Ensino Odontológico. ABOL orienta sobre conteúdos da disciplina de Odontologia Legal. Disponível em: http://www.abeno. org.br/noticias/noticia020.php.

20 Gonçalves ER, Verdi MIM. Os problemas éticos no atendimento a pacientes na clínica odontológica de ensino. Ciênc Saúde Col. 2007;12(3):755-64.

\section{ABSTRACT \\ Forensic Dentistry education in Brazil: an invitation to reflection}

In recent years the education in Forensic Odontology has undergone significant changes to meet social demands requested, as a result of the intense modifications in the modern society. The new professional has received important information about the labour market, which will help them to carry out clinical activities within a admnistrative, ethical and legal context, besides that it will help them to have a glimpse of the new perspectives of the area. Considering the above scenario, this paper aims to present points to reflection regarding the teaching-learning process. From several discussions held by the Brazilian Association of Forensic Odontology (ABOL) and the Brazilian Association for Dental Education (ABENO), the current aspects of teaching in this area were merged into this article, highlighting the need of joint work of all the IES interested in the teachinglearning process in dentistry.

Descriptors: Forensic Dentistry. Education, Dental. Education, Higher.

Correspondência para:

Prof. Hélion Leão Lino-Júnior

E-mail: helionlinojunior@uel.com.br

Universidade Estadual de Londrina -

UEL

Rua Pernambuco, 540 - Centro

86020-070 Londrina - PR 